\title{
Integrated care and optimal management of pulmonary arterial hypertension
}

This article was published in the following Dove Press journal:

Journal of Multidisciplinary Healthcare

II May 2009

Number of times this article has been viewed

\section{Geoff Strange' \\ Robin Fowler ${ }^{2}$ \\ Corina Jary ${ }^{2}$ \\ Brad Dalton ${ }^{3}$ \\ Simon Stewart ${ }^{4}$ \\ Eli Gabbay ${ }^{5}$}

'Epidemiology and Preventative Medicine, Monash University, VIC, Australia; ${ }^{2}$ Royal Perth Hospital and Curtin University, Perth,WA, Australia; ${ }^{3}$ University of Tasmania, Launceston, TAS, Australia; ${ }^{4}$ Baker Heart Research Institute, Melbourne, VIC, Australia; ${ }^{5}$ Royal Perth Hospital and University of Western Australia, Perth,WA, Australia
Correspondence: Geoff Strange C/o Advanced Lung Disease Clinic, GPO Box X2213, Perth,WA

$\mathrm{Tel}+6 \mathrm{I} 892248793$

Fax +6I 892243866

Email gastrI@student.monash.edu

\begin{abstract}
Pulmonary arterial hypertension (PAH) may occur as an idiopathic process or as a component of a variety of diseases, including connective tissue diseases, congenital heart disease, and exposure to appetite suppressants or infectious agents such as HIV. Untreated, it is a potentially devastating disease; however, diagnosis can be difficult due to the non-specific nature of symptoms during the early stages, and the fact that patients often present to a range of different medical specialties. The past decade has seen remarkable improvements in our understanding of the pathology associated with the condition and the development of PAHspecific therapies with the ability to alter the natural history of the disease. This article reviews the evidence for screening and diagnosis of susceptible patient groups and discusses treatment selection and recommendations based on data available from randomized controlled trials. In addition, due to the complexity of the diagnostic evaluation required and the treatment options available, this review mandates for a multidisciplinary approach to the management of PAH. We discuss the roles and organizational structure of a specialized PAH center in Perth, Western Australia to highlight these issues.
\end{abstract}

Keywords: pulmonary hypertension, multidisciplinary care, systemic sclerosis, diagnostic protocol

\section{Introduction}

Pulmonary arterial hypertension (PAH) is a group of diseases which form a subset of those with pulmonary hypertension (PHT). PAH occurs as an idiopathic process (iPAH) or as a component of a variety of disease processes, including connective tissue diseases (CTD), congenital heart disease, and exposure to exogenous factors including appetite suppressants or infectious agents such as human immunodeficiency virus (HIV). All of these conditions share a common pattern of vascular remodeling of the small pulmonary arteries. An increase in pulmonary vascular resistance (PVR) results in progressive dyspnea, profound functional limitation, and if untreated, progression to right ventricular failure and death. ${ }^{1}$

$\mathrm{PAH}$ is often perceived as a disease with a uniformly poor outcome. However, the past decade has witnessed significant advances in PAH-specific therapies with the ability to change the course of the disease. For example, untreated PAH has an estimated median survival of 2.8 years, with 1-year, 3-year, and 5-year survival rates of $68 \%, 48 \%$ and $34 \%$, respectively. ${ }^{2}$ In contrast, a prospective study of observed survival in 139 patients with iPAH treated with bosentan and 346 similar patients treated with epoprostenol, reported survival estimates after 1 and 2 years of 97\% and $91 \%$, respectively, in the bosentan cohort and $91 \%$ and $84 \%$ in the epoprostenol 
cohort. ${ }^{3}$ In patients with CTD-related PAH, earlier treatment is associated with better outcomes - the risk of death increasing by $11 \%$ for every $10 \mathrm{mmHg}$ increase in mean pulmonary arterial pressure (mPAP). ${ }^{4}$ Unfortunately, given the range of comorbidities associated with the disease, and the fact that various specialities can be confronted with $\mathrm{PAH}$, translating the importance of early diagnosis and treatment into clinical practice represents an ongoing challenge.

In the initial stages, the most common symptoms of $\mathrm{PAH}$ include breathlessness, fatigue and near syncope. ${ }^{5}$ Since these symptoms are non-specific, PAH is often overlooked or under-recognized until its later, more advanced stages (such as the onset of right heart failure). This pattern of presentation may also be responsible for underestimating the true prevalence of the disease and explain, in part, why PAH is sometimes managed by cardiologists and sometimes by respiratory physicians. The aim of this article is twofold. Firstly, to provide an overview of $\mathrm{PAH}$ and appropriate diagnostic and treatment approaches, and secondly, to discuss the rationale and importance of a multidisciplinary approach to the management of this disease. The process of integrated
PAH care provided by the Royal Perth Hospital, Western Australia is used as the basis for this discussion.

\section{Classification and pathophysiology of PAH \\ Classification}

PHT is defined by a mPAP $>25 \mathrm{mmHg}$ at rest or $>30 \mathrm{mmHg}$ with exercise. In 2003, the World Health Organization (WHO) revised the classification of PHT into five categories based in part on etiology: PAH, pulmonary venous hypertension, PHT associated with lung diseases and/or hypoxemia, PHT resulting from chronic thrombotic or embolic disease, and miscellaneous (Table 1). ${ }^{6}$ The classification system aims to frame whether PHT is a manifestation of an underlying disease and provides an understanding of the contexts in which PHT occurs. PAH is a sub-category of PHT (the two terms are not synonymous) and is defined as a mPAP $>25 \mathrm{mmHg}$ at rest or $>30 \mathrm{mmHg}$ during exercise with a normal pulmonary artery wedge pressure (PAWP) which excludes pulmonary venous hypertension. ${ }^{7-9}$ Patients with PAH can also be classified according to their ability to function and symptom

Table I Revised clinical classification of pulmonary hypertension (Venice 2003) ${ }^{6}$

\section{Pulmonary arterial hypertension (PAH)}

I.I. Idiopathic (IPAH)

1.2. Familial (FPAH)

I.3. Associated with (APAH):

1.3.I. Collagen vascular disease

1.3.2. Congenital systemic-to-pulmonary shunts

1.3.3. Portal hypertension

1.3.4. HIV infection

1.3.5. Drugs and toxins

I.3.6. Other (thyroid disorders, glycogen storage disease, Gaucher disease, hereditary hemorrhagic telangiectasia, hemoglobinopathies, myeloproliferative disorders, splenectomy)

1.4. Associated with significant venous or capillary involvement

I.4.I. Pulmonary veno-occlusive disease (PVOD)

1.4.2. Pulmonary capillary hemangiomatosis $(\mathrm{PCH})$

1.5. Persistent pulmonary hypertension of the newborn

2. Pulmonary hypertension with left heart disease

2.I. Left-sided atrial or ventricular heart disease

2.2. Left-sided valvular heart disease

3. Pulmonary hypertension associated with lung diseases and/or hypoxemia

3.I. Chronic obstructive pulmonary disease

3.2. Interstitial lung disease

3.3. Sleep-disordered breathing

3.4. Alveolar hypoventilation disorders

3.5. Chronic exposure to high altitude

3.6. Developmental abnormalities

4. Pulmonary hypertension due to chronic thrombotic and/or embolic disease

4.I. Thromboembolic obstruction of proximal pulmonary arteries

4.2. Thromboembolic obstruction of distal pulmonary arteries

4.3. Non-thrombotic pulmonary embolism (tumor, parasites, foreign material)

5. Miscellaneous: Sarcoidosis, histiocytosis X, lymphangiomatosis, compression of pulmonary vessels (adenopathy, tumor, fibrosing mediastinitis) 
severity. The WHO classification of functional capacity, an adaptation of the New York Heart Association (NYHA) system, has been useful in this regard (Table 2). ${ }^{10}$

Regardless of the cause, the common end result of processes leading to PAH is elevation of PVR, with resultant elevation of PAP and progression to right-sided heart failure.

\section{Pathophysiology}

Under normal conditions, the pulmonary circuit is a low pressures system (mPAP 12-16 mmHg). Healthy individuals can accommodate up to a 4-fold rise from the resting cardiac output with little increase in PAP, due to distensibility of the thin-walled pulmonary vasculature and to recruitment of vessels that are normally closed when at rest. ${ }^{11}$ The excess capacity is such that approximately $70 \%$ of the vascular bed must be lost before there is an increase in resting PAP. ${ }^{11}$

Most forms of PAH share a common pathophysiology which includes pulmonary vasoconstriction, vascular wall hypertrophy and thrombosis in situ. ${ }^{12-14}$ The primary mechanism is believed to involve endothelial dysfunction, resulting in over expression of endothelin (ET)-1, a 21-amino acid peptide which, at normal levels contributes to the maintenance of vascular tone, mediates cardiac, renal and endocrine function, and plays a role in mitogenesis. ${ }^{15}$ Endothelial dysfunction also reduces the synthesis of nitric oxide and prostacyclin $\left(\mathrm{PgI}_{2}\right)$, impairing vasodilatory responses and exacerbating the dysfunctional vasoresponses caused by elevated ET levels. ${ }^{14,16}$ Other important pathways in the process of pulmonary vascular remodeling include changes in potassium channel expression, activation of vascular elastases, and increased expression of inflammatory chemokines. ${ }^{17}$ Various growth factors, including platelet-derived growth factor (PDGF), fibroblast growth factor (FGF), insulin growth factor-1 (IGF-1), and epidermal growth factor (EGF) have also been postulated to be involved. ${ }^{18}$

A mutation of the bone morphogenetic protein receptor type II (BMPR2) gene has been identified in approximately $50 \%$ patients with familial and $\mathrm{PAH} .{ }^{19}$ However, the relationship of this gene mutation to the broad range of associated causes of PAH remains unknown, and not all individuals carrying the BMPR2 mutation develop PAH. A subject who possesses the mutation has a $10 \%$ to $20 \%$ lifetime risk of acquiring $\mathrm{PAH}$, while an individual without the mutation has a lifetime risk of $\mathrm{PAH}$ no different to the general population. ${ }^{19}$

Despite the multitude of perturbations that have been demonstrated in clinical PAH as well as in animal models of pulmonary hypertension, it remains unclear which are "causes" versus consequences of this disorder. However, the end result includes increased vasoconstriction, smooth muscle cell proliferation, decreased vasodilation, and fibrotic changes in medium- to small-sized pulmonary arteries. ${ }^{12-14}$

Both vasoconstrictive and hypertrophic changes lead to increased PVR, increasing the workload of the right ventricle. Initially, the right ventricle compensates to maintain adequate pulmonary flow, but as the increased workload causes the right ventricle to dilate, efficiency eventually falls. Symptoms such as dyspnea and fatigue appear, initially on exertion. Eventually and often suddenly, the right ventricle decompensates and right heart failure ensues. ${ }^{20}$ Death occurs as a result of end-stage right heart failure or arrhythmia. ${ }^{21}$

As a result of the interconnection between pulmonary and cardiac pathologies, the diagnosis of PAH remains clinically challenging, with an umbrella of potential presentations. Furthermore, various specialities can be confronted with patients with PAH (eg, cardiologists, respiratory physicians and rheumatologists). It is this diverse and often non-specific presentation of patients that provides justification for a multidisciplinary approach to the detection and management of PAH.

\section{Epidemiology}

The incidence of idiopathic and familial PAH in the general population is almost certainly higher than the historical estimate of 1 to 2 per million population. ${ }^{10}$ More recent estimates vary from 5 to 52 cases per million population. ${ }^{22,23}$ iPAH may manifest in both genders and all ages. During

Table 2 Modified New York Heart Association classification of functional status in patients with pulmonary hypertension (PHT)

Class I Patients with PHT but without resulting limitation of physical activity. Ordinary physical activity does not cause undue dyspnea or fatigue, chest pain, or near syncope.

Class II Patients with PHT resulting in slight limitation of physical activity. They are comfortable at rest. Ordinary physical activity causes undue dyspnea or fatigue, chest pain, or near syncope.

Class III Patients with PHT resulting in marked limitation of physical activity. They are comfortable at rest. Less-than-ordinary physical activity causes undue dyspnea or fatigue, chest pain, or near syncope.

Class IV Patients with PHT with inability to carry out any physical activity without symptoms. These patients manifest signs of right heart failure. Dyspnea and/or fatigue may even be present at rest. Discomfort is increased by any physical activity. 
childhood, the condition affects both genders equally. ${ }^{24}$ After puberty however, detection is more frequent in females (approximately $2: 1$ ratio). ${ }^{25,26}$

For other causes, PAH is associated with scleroderma in $4.9 \%$ to $38.6 \%$ of patients, ${ }^{27-31}$ a condition which itself has a point prevalence of between 30.8 and 286 cases per million population. ${ }^{21}$ Taken together, these estimates indicate that the prevalence of PAH in the community may be much higher than previously proposed. Recently, a retrospective database review of all patients undergoing Doppler echocardiographic measures in a major regional cardiology center identified a significant number of patients with $\mathrm{PAH}$, subsequently confirmed by right-heart catheterization (RHC). The estimated minimum prevalence of PAH in this community was 75.2 cases per million population (47.9 case per million for $\mathrm{PAH}$ and 27.4 cases per million for scleroderma-related PAH). ${ }^{32}$

\section{Diagnosis and screening Clinical presentation}

Despite the gravity of the disease, detection of $\mathrm{PAH}$ remains elusive until the later stages of the disease, owing to the often subtle and non-specific nature of symptoms (Table 3 ). Symptoms are often difficult to dissociate from those caused by a known underlying pulmonary or cardiac disorder and frequently, there is a delay of up to 3 years between first symptoms and diagnosis ${ }^{33}$ - an interval that has remained stable over the last 20 years. The most common symptoms - exertional dyspnea and fatigue - reflect an inability to increase cardiac output during activity. Typical angina may also occur despite normal coronary arteries. The mechanism is unclear, but anginal chest pain may be due to pulmonary artery stretching or right ventricular ischemia. ${ }^{34}$ Over time, increasing fatigue, palpitations, chest pain, and increasing exercise intolerance develop, while hypoxemia, syncope and right-sided heart failure are markers of end-stage disease.

Since PHT may be associated with a variety of comorbid conditions, past medical history and symptomatic evidence of

Table 3 Symptoms and signs of pulmonary hypertension ${ }^{34}$

\begin{tabular}{ll}
\hline Symptoms & Signs \\
\hline Dyspnea on exertion & Jugular vein distention \\
Fatigue & Prominent right ventricular impulse \\
Syncope & Accentuated pulmonic valve component (P2) \\
Anginal chest pain & Right-sided third heart sound (S3) \\
Hemoptysis & Tricuspid insufficiency murmur \\
Raynaud's phenomenon & Hepatomegaly \\
& Peripheral edema \\
\hline
\end{tabular}

a related illness should also be considered. Potential exposure to toxic agents should be explored. This includes previous use of appetite suppressants and chemotherapy agents (including mitomycin-C, carmustine, etoposide, cyclophosphamide and bleomycin). Known exposure to HIV infection should also be considered together with a history of pulmonary embolism or deep vein thrombosis. ${ }^{19}$ Orthopnea and paroxysmal nocturnal dyspnea suggest elevated pulmonary venous pressure and pulmonary congestion due to left-sided cardiac disease. Raynaud phenomenon, arthralgias, or swollen hands and other symptoms of CTD in the setting of dyspnoea should raise the possibility of PAH related to CTD. A history of snoring or apnea provided by the patient's partner warrants evaluation for sleep-disordered breathing as a potential causative or contributory factor. ${ }^{19}$

\section{Diagnosis}

The diagnosis of PAH is, in part, through the exclusion of other diseases that cause PHT. Formal guidelines have been published by the European Society of Cardiology (ESC) ${ }^{7}$ and the American College of Chest Physicians (ACCP), ${ }^{8,19,35}$ while systemic sclerosis groups have published proposed assessment pathways for the detection of PAH in this cohort. ${ }^{20}$ Assessment follows a logical sequence of determining whether there is a risk of $\mathrm{PAH}$ being present, whether $\mathrm{PAH}$ is likely to be present based on initial, non-invasive evaluation, clarifying the underlying etiology of $\mathrm{PAH}$, and delineating the specific hemodynamic profile, including the acute response to vasodilator testing. ${ }^{19}$

\section{Physical examination}

Clinical suspicion should arise in any patient presenting with breathlessness without overt signs of specific heart or pulmonary disease, particularly in diseases which may be associated with $\mathrm{PAH} .{ }^{33}$ On physical examination, the likelihood of PAH increases when certain findings are present. For example, a left parasternal lift produced by the impulse of the hypertrophied right ventricle, an accentuated pulmonary component of the second heart sound (S2), pansystolic murmur of tricuspid regurgitation, diastolic murmur of pulmonary insufficiency, right ventricular S3, jugular vein distention, hepatomegaly, peripheral edema, ascites and cool extremities. ${ }^{19,35}$ However, the absence of these findings does not exclude PAH.

\section{Electrocardiogram}

The electrocardiogram (ECG) lacks sufficient sensitivity to serve as an effective screening tool for PAH. However, it does provide important prognostic information on anatomical 
and arrhythmic problems. ECG changes associated with $\mathrm{PAH}$ include right ventricular hypertrophy and right axis deviation in $87 \%$ and $79 \%$ of patients, respectively. ${ }^{19,35}$

\section{Chest X-ray}

In the majority of patients with mild $\mathrm{PAH}$, a chest X-ray (CXR) is normal. In more advanced disease, signs suggestive of PAH include enlarged main and hilar pulmonary arterial shadows with concomitant attenuation of peripheral pulmonary vascular markings ('pruning'). Right ventricular enlargement is often detected by impingement of the anteriorly situated right ventricle silhouette into the retrosternal clear space on the lateral CXR. ${ }^{19,35}$

\section{Pulmonary function tests}

In the diagnosis of PAH, pulmonary function tests (PFTs) are used to exclude significant lung disease. Although lung function abnormalities have been described in association with PAH they are generally mild and unlikely to be the primary cause of symptoms. The exception is a marked impairment in the diffusion capacity for carbon monoxide $\left(\mathrm{DL}_{\mathrm{CO}}\right)$ associated with systemic sclerosis. The $\mathrm{DL}_{\mathrm{CO}}$ of $20 \%$ of patients with limited systemic sclerosis is below normal; however, a $\mathrm{DL}_{\mathrm{CO}}$ of $<55 \%$ of predicted increases the likelihood of the presence or future development of PAH. ${ }^{19,35}$

\section{Ventilation-perfusion $(\mathrm{V} / \mathrm{Q})$ lung scanning}

V/Q lung scans are an important component of assessment and should be performed to rule out chronic thrombolic pulmonary hypertension (CTEPH), a potentially curable cause of PHT. ${ }^{19,35}$ Patients with PHT who have normal V/Q scans are unlikely to have chronic pulmonary embolism and more likely to have iPAH. In three studies, V/Q scanning showed sensitivity of $90 \%$ to $100 \%$ with a specificity of $94 \%$ to $100 \%$ for distinguishing between iPAH and CTEPH. A positive V/Q scan in patients with CTEPH generally shows one or more segmental-sized or larger mismatched perfusion defects and warrants pulmonary angiography for definitive diagnosis. ${ }^{19,35}$

\section{Assessment of exercise capacity}

Assessment of exercise capacity, using the 6-minute walk test (6MWT) or cardiopulmonary exercise testing is an important part of the evaluation of PAH. The goals of exercise testing include, but are not limited to: determining maximal exercise tolerance; identifying functional capacity; obtaining prognostic data; uncovering PHT silent at rest; establishing a baseline measure of exercise capacity and following the response to therapy. Furthermore, the assessment of exercise capacity may provide evidence of contributory reasons for symptoms (eg, myocardial ischemia). ${ }^{19,35}$

\section{Doppler echocardiogram}

When PAH is suspected Doppler echocardiography should be employed to assess pulmonary artery systolic pressure (PASP), right ventricular enlargement (RVE), right atrial enlargement (RAE) and RV dysfunction. ${ }^{19,35}$ An adequate Doppler signal from the tricuspid regurgitation jet is required to estimate PASP and this may be absent in approximately $25 \%$ of patients. ${ }^{36}$ Furthermore, the parameters for estimating PASP and abnormal thresholds for defining PAH have not been standardized. Peak velocity of the tricuspid regurgitant jet (TRV), a range of tricuspid gradients, and RVSP have all been used. ${ }^{20}$ To exclude PHT due to left-heart disease, left ventricular systolic and diastolic function and valve morphology and function should also be assessed. Finally, echocardiography with contrast should be used to identify or rule out PAH due to congenital heart disease (eg, abnormal morphology; shunt).

\section{Right-heart catheterization}

$\mathrm{RHC}$ is required to confirm the presence of PAH, establish the specific diagnosis including exclusion of pulmonary venous hypertension, determine the severity of hemodynamic impairment, test the vasoreactivity of the pulmonary circulation, and to guide subsequent therapy. ${ }^{19,35}$ A response to a vasodilator challenge indicates that a patient may be suitable for a trial of high dose calcium-channel blockers (CCBs). A PCWP $>15 \mathrm{mmHg}$ may indicate left heart disease and requires careful evaluation as $\mathrm{PAH}$ specific therapies may be contraindicated.

\section{Screening}

High risk conditions and the likelihood of having $\mathrm{PAH}$ are shown in Table 4. The ACCP Consensus Statement recommends that patients with scleroderma should undergo periodic Doppler echocardiography as part of a screening program because of the relatively high detection rates of PAH and disease severity when it develops. ${ }^{19}$ Other potential causes of PAH do not warrant routine screening (eg, previous use of appetite suppressant, HIV infection, other CTDs) because of the low likelihood of discovering PAH. The question of when to begin screening in patients with the potential for having familial PAH remains open. Patients with more than one family member with PAH related to a mutation in the BMPBR2 gene might be considered for genetic testing, since a negative test would imply that there is no higher than 
Table 4 Patients at risk of developing pulmonary arterial hypertension ${ }^{37}$

\begin{tabular}{|c|c|}
\hline Patient characteristics & Risk profile \\
\hline Patients with known genetic mutations predisposing to $\mathrm{PAH}$ & $20 \%$ chance of developing PAH \\
\hline First degree relatives in a FPAH family & $10 \%$ chance of developing PAH \\
\hline Scleroderma spectrum of disease & $27 \%$ prevalence of $\mathrm{PAH}(\mathrm{RSVP}>40 \mathrm{mmHg})$ \\
\hline Portal hypertension in patients considered for liver transplantation & $5 \%$ prevalence of PAH (mPAP $>25 \mathrm{mmHg}$ and PVR $>3.0 \mathrm{U})$ \\
\hline Congenital heart disease with systemic to pulmonary shunts & Likely approximately $100 \%$ in high flow, non-restrictive L-R shunts \\
\hline Use of flenfluramine appetite suppressants ( $>3$ months) & $\begin{array}{l}\text { Prevalence of } 136 / \text { million users based on odds ratio of } 23 \text { times } \\
\text { background }\end{array}$ \\
\hline HIV infection & Prevalence $0.5 / 100$ \\
\hline Sickle cell disease & Prevalence $9.0 / 100($ TRV $>3.0)$ \\
\hline
\end{tabular}

Abbreviations: PHT, pulmonary hypertension; PAH, pulmonary arterial hypertension; FPAH, familial pulmonary arterial hypertension; RSVP, right ventricular systolic pressure; mPAP, mean pulmonary arterial pressure; PVR, pulmonary vascular resistance; L-R, left-to right; HIV, human immunodeficiency virus; TRV, tricuspid regurgitation velocity; RHC, right heart catheterization.

normal risk of developing PAH. However, any test should be preceded by extensive family and genetic counseling. ${ }^{37}$

The availability of new therapies that have been shown to slow or prevent progression of PAH has caused a growing interest among physicians to diagnose PAH at an early stage. Since the range of diagnostic tests required is broad, and often specialized in itself, multidisciplinary clinics, consisting of a rheumatologist, cardiologist, respiratory physician and a specialist nurse together with allied health services (eg, sonography, physiotherapy and radiology) appear warranted. Given the complex nature of PAH, there can be little doubt, that such clinics would facilitate early diagnosis and facilitate access to available therapies according to best practice guidelines. $^{38}$

\section{Treatment approaches and priorities}

The treatment of PAH has witnessed a dramatic change in the past decade. Management guidelines for PAH have been published by the $\mathrm{ESC}^{7}$ and the ACCP. ${ }^{39-41}$ Both of these guidelines are in the process of being updated with new publications due in 2009. Furthermore, the National Pulmonary Hypertension Centres of the United Kingdom and Ireland recently released an updated consensus statement on the management of PAH in clinical practice. ${ }^{33}$ Treatment is often complex and patients benefit from referral to a center that specializes in the treatment of this disorder. ${ }^{34}$ Here we will consider 'conventional' therapy, defined as that which has been used for patients with PAH in the years prior to the development of disease-specific, targeted therapy, and PAH-specific therapy separately. An evidence-based treatment algorithm is also proposed. The intention is to provide a guide to the selective use of each form of therapy.

\section{Conventional treatment}

The aim of therapy in patients with $\mathrm{PAH}$ is to improve survival, disease-related symptoms and quality of life (QoL). Conventional treatment options include oxygen therapy in cases of hypoxemia, anticoagulants such as warfarin, digoxin and diuretics in cases of right-sided heart failure. If, during RHC, the pulmonary vasoreactive tests are positive, the treatment of choice is high-dose CCBs, as improved survival with long-term use has been demonstrated in this cohort of patients. ${ }^{42,43}$ Vasoreactivity is considered to be present when the mPAP has decreased by at least $10 \mathrm{mmHg}$ to $40 \mathrm{mmHg}$ or less with normal or high cardiac output after intervention with pulmonary vasodilators, such as $100 \%$ oxygen, nitric oxide inhalation or intravenous prostacyclin. ${ }^{35}$ However, less than $10 \%$ of patients with iPAH respond long term to CCB therapy and even less in other associated conditions, such as PAH related to CTD: in many cases the test is omitted because the response is so infrequent. ${ }^{35}$ For well over $90 \%$ of patients, PAH specific therapies are indicated first line.

\section{Specific treatment}

Classes of drugs available for the treatment of PAH include prostanoids (epoprostenol and iloprost), endothelin receptor antagonists (ERAs, bosentan, sitaxsentan and ambrisentan) and a phosphodiesterase-5 (PDE-5) inhibitor (sildenafil). These drugs offer improved symptom control, exercise capacity, QoL and cardiopulmonary hemodynamics, as well as the prospect of extended survival. However, due to the short-term nature of the randomized controlled trials (12-16 weeks), only epoprostenol has demonstrated a survival benefit compared to patients treated with conventional therapy. ${ }^{44}$ Figure 1 presents a proposed algorithm for the therapeutic management of 
patients with PAH. ${ }^{45}$ This algorithm is based on evidence from clinical trials performed to date and is focused on patients in NYHA functional class II to IV. Furthermore, the algorithm is based on therapies that have been evaluated in $\mathrm{PAH}$, and in PAH associated with scleroderma or due to anorexigens. Extrapolation of trial results to other PAH subgroups should be done with caution.

For patients classified as NYHA class II, III or IV, there are a number of therapeutic options. Bosentan is an oral dual endothelin- $\mathrm{A}\left(\mathrm{ET}_{\mathrm{A}}\right)$ and endothelin- $\mathrm{B}\left(\mathrm{ET}_{\mathrm{B}}\right)$-receptor antagonist. It is the first molecule of this class of drugs to be synthesized. Activation of $\mathrm{ET}_{\mathrm{A}}$ and $\mathrm{ET}_{\mathrm{B}}$-receptors on smooth muscle cells mediate the vasoconstrictive and mitogenic effects of ET-1, and the prominent role of ET-1 in the pathogenesis of PAH has been well documented. ${ }^{46,47}$ The efficacy of bosentan has been extensively studied in five randomized placebo-controlled trials $^{48-52}$ and five open-label studies. ${ }^{53-57}$ In these trials, bosentan demonstrated improvements in exercise capacity, functional class, hemodynamics, echocardiographic and Doppler variables, and time to clinical worsening. Additional ERAs have since been developed (eg, sitaxsentan and ambrisentan) that target the $\mathrm{ET}_{\mathrm{A}}$ receptor only, with similar efficacy results. Slightly less long-term evidence is available for these agents. ${ }^{58-61}$

The prostacyclin analogue, epoprostenol has been approved for the treatment of patients with iPAH in NYHA class III and IV. In several randomized controlled trials, the beneficial effects of epoprostenol were demonstrated on survival, exercise tolerance, functional class and pulmonary vascular hemodynamics. ${ }^{44,62-64}$ Despite its benefits, the complexity of drug administration limit its use. Epoprostenol is recommended first line for those patients presenting with functional class IV symptoms. Several additional prostacylin analogues, namely iloprost, treprostinil and beraprost, have also been developed with less utility than epoprostenol.

More recently, sildenafil, an oral PDE-5 inhibitor, has been shown to be effective in patients with iPAH ${ }^{65}$ PDE-5 exerts its pharmacological effect by increasing the intracellular concentration of cGMP. The increase of this nucleotide induces relaxation and antiproliferative effects on vascular smooth muscle cells. ${ }^{7}$

For patients in functional class II-III, therapeutic efficacy of the PAH-specific agents is evaluated after 3 months and every 3 to

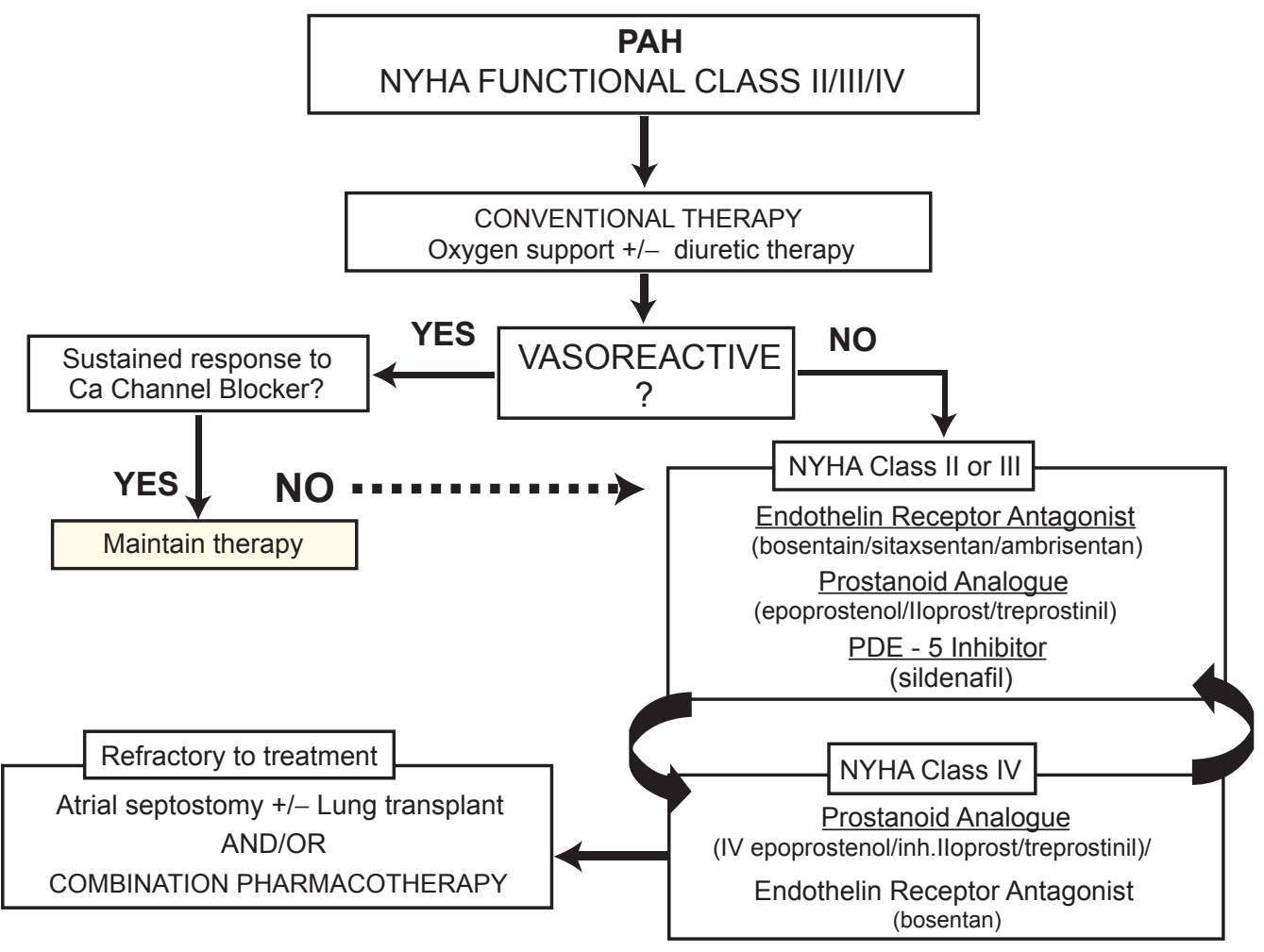

Figure I Proposed algorithm for the medical management of pulmonary arterial hypertension (PAH). ${ }^{41}$ A positive acute response to vasodilators is defined as a fall in mPAP of at least $10 \mathrm{mmHg}$ to $40 \mathrm{mmHg}$, with an increased or unchanged cardiac output during acute challenge with inhaled nitric oxide, iv epoprostenol, or iv adenosine. Sustained response to calcium channel blockers is defined as patients being in functional class I or II with near-normal hemodynamics after several months of treatment. Most experts recommend that patients in functional class IV in unstable condition be treated with iv epoprostenol. In patients in functional class III, first-line therapy may include oral endothelin-receptor antagonists, phosphodiesterase inhibitors, long-term iv epoprostenol, or prostanoid analogues.

Abbreviation: PDE, phosphodiesterase. 
6 months thereafter and more frequently in functional class IV. If treatment with initial therapy fails, the next treatment option, usually an agent with a different mode of action is administered, or continuous intravenous epoprostenol considered.

\section{Combination therapy}

The optimal management of patients who exhibit clinical deterioration despite targeted monotherapy remains a matter of debate. ${ }^{33}$ Follow-up beyond the first 3 months of therapy with oral, inhaled or intravenous agents shows that a proportion of patients deteriorate. For example, the percentage of patients remaining stable on bosentan monotherapy at 1 year is $85 \%,{ }^{66}$ and $57 \%$ at 3 years. ${ }^{67}$ Similarly, for sildenafil monotherapy, $85 \%$ of patients are stable at 1 year, ${ }^{65}$ as are $85 \%$ on epoprostenol $^{64}$ and $42 \%$ to $77 \%$ on inhaled iloprost. ${ }^{68,69}$ With the development of several therapeutic agents with different mechanisms of action and potential synergy, considerable interest has developed in the possibility of combination therapy.

At the time of writing, concomitant combination therapy has not been adequately studied. The single small trial of epoprostenol initiation with add on bosentan 48 hours later showed only trends in improvement, without significant benefits. ${ }^{37}$ In contrast, sequential add on therapy has achieved successful endpoints for a wide range of combinations (eg, bosentan add iloprost, epoprostenol add sildenafil, bosentan add sildenafil, beraprost or iloprost add bosentan, treprostinil add bosentan, and iloprost add sildenafil). ${ }^{37}$ For example, in the PACES-1 trial, Simonneau et al randomized 267 patients with Class III or IV disease (iPAH, CTD-related PAH or CHD-PAH) receiving epoprostenol continuous iv infusion, to either added sildenafil or placebo. ${ }^{70}$ At 16 weeks, sequential therapy significantly improved 6MWD compared to monotherapy (+26 m; p $<0.001)$, decreased mPAP ( $<<0.001)$, and increased time to clinical worsening $(p=0.012)$.

Combination therapy remains an attractive option, and individuals who demonstrate an inadequate response to monotherapy should be considered for a combination of two or more disease-targeted therapies. However, given the limited amount of conclusive data pertaining to combination treatment, published guidelines have so far made no specific recommendation to guide clinicians on the next step to improve the status of their patients who continue to decline on monotherapy. ${ }^{33}$

\section{Transplant}

A small proportion of patients with $\mathrm{PAH}$ are eligible for heart-lung or bilateral lung transplantation. This treatment option should be considered and early discussion with experienced transplant physicians is recommended. However, limited donors supply and a 5-year survival of approximately $50 \%$, significantly restricts its utlility. ${ }^{71}$ Consideration should be given to referring patients to centers that are experienced in atrial septostomy where available. ${ }^{72}$

\section{Patient management issues and non-drug interventions}

PAH is a chronic, life-shortening disease and many patients suffer from limitations in their physical mobility, energy, emotional reactions and social isolation. It is therefore essential that the multidisciplinary team involved with the care of patients with PAH is highly skilled in managing the burden and impact of the disease, and its complex and often intrusive therapies at both physical and psychological levels. Understandably, many PAH patients are affected by a degree of anxiety and/or depression that can have a profound impact on their QoL. Assisting patients to adapt to the uncertainty associated with their illness is important, as is referral to psychologists or psychiatrists when needed. Support groups for patients, families and carers are useful in improving the understanding and the acceptance of the disease condition.

QoL has been shown to be low in patients with PAH using the 36-Item Short-Form Health Survey (SF-36), ${ }^{73}$ the Nottingham Health Profile (NHP), the Congestive Heart Failure Questionnaire (CHQ) and the Hospital Anxiety and Depression Scale (HADS). ${ }^{1}$ Improvements in QoL have been reported in trials of $\mathrm{PAH}$-specific therapy and improvements over pre-treatment scores have been seen in association with increased exercise capacity. ${ }^{44,74-79}$ However, exercise capacity and QoL in patients with PAH are not necessarily related. One study found an absence of any significant relationship in changes in 6MWT distance and changes in QoL in response to therapy, ${ }^{80}$ concluding that these measures provide complementary data in terms of response to therapy. A new disease specific patient report outcome instrument, CAMPHOR has recently been developed and correlates well with current surrogate outcomes. An assessment such as CAMPHOR should be used in routine clinical practice to assess the QoL status of patients with PAH. ${ }^{33}$

$\mathrm{PAH}$ is a contraindication to pregnancy. Patients with $\mathrm{PAH}$ require counseling regarding the very high risk of pregnancy-related mortality (approx. 30\%) and the need for adequate contraception. Although the WHO advises discussing termination in the event of pregnancy, if a patient is fully informed and understands the risks of proceeding with pregnancy, treatment with some $\mathrm{PAH}$-specific therapies may 
represent a realistic option and may improve the chances of maternal survival. ${ }^{33}$

Finally, patients should be also be encouraged to be as active as their symptoms allow. ${ }^{33}$ A recent study has demonstrated an improvement in exercise capacity in patients who took part in a training program. ${ }^{81}$

\section{Optimal structure and organization of multidisciplinary care}

Effective diagnosis and treatment of PAH, where several clinical pathways and scenarios are possible, relies on the expertise of many clinical specialties with the knowledge and skill to meet the holistic needs of the patient and their carers. ${ }^{33}$ These needs include information about the disease and its prognosis, education and support in managing complex drug therapies, psychological and social support, and access to local support in the community. It stands to reason that this care is best achieved when these specialists work together in multidisciplinary teams.

Multidisciplinary care involves a team approach to the provision of care by multiple medical and allied health disciplines. The liaison and cooperation of team members together with the patient ensures that all relevant treatment methods that have a place in the modern management of PAH are properly considered - from diagnosis through follow-up. The effectiveness of multidisciplinary care and coordinated specialty units has been well documented in other conditions, namely heart failure, ${ }^{82}$ stroke ${ }^{83,84}$ and oncology ${ }^{85}$
To date, however, there is no comprehensive information describing how, or to what extent, institutions managing PAH in Australia have adopted a multidisciplinary approach. In Western Australia, the state referral center for PAH is located at the Royal Perth Hospital. The composition and roles of the multidisciplinary team are shown in Table 5. We conducted independent observations and interviews with members of the team to elicit further information about the organization, style, leadership and benefits of the multidisciplinary approach.

At this center, patients suspected of having PAH are first seen by a specialist nurse coordinator. The mode of referral is variable. Some patients may be identified by hospital physicians or family doctors as outpatients. Others are referred from related initiatives such as the scleroderma screening program. ${ }^{38}$ The nurse coordinator is responsible for organizing initial screening examinations including echocardiography, ECG and CXR. Once this information is collated, the patient is seen by a respiratory physician. When required, additional assessments are organized by the nurse coordinator, and may include consultation with a cardiologist. If the results of the examinations are indicative of PAH, RHC is carried out. After the results of all tests have become available, patients are discussed by the multidisciplinary team, appropriate treatment is discussed and a management plan developed. The management plan is then proposed to the patient during a follow up visit. All consenting patients with confirmed $\mathrm{PAH}$ are entered into a PAH registry.

Table 5 Composition and roles of the Royal Perth Hospital PAH multidisciplinary team

\begin{tabular}{|c|c|}
\hline Discipline & Role \\
\hline Team coordinator & Organization of resources, administration meetings and educational sessions \\
\hline Respiratory medicine & $\begin{array}{l}\text { Diagnostic evaluation; medical treatment; patient and family education; staff and trainee education; research; program } \\
\text { evaluation }\end{array}$ \\
\hline Cardiology & $\begin{array}{l}\text { Diagnostic evaluation; medical treatment; patient and family education; staff and trainee education; research; program } \\
\text { evaluation }\end{array}$ \\
\hline Rheumatology & $\begin{array}{l}\text { Diagnostic evaluation; medical treatment; patient and family education; staff and trainee education; research; program } \\
\text { evaluation }\end{array}$ \\
\hline Nursing & Assessment and provision of care needs; support and education for patients and families \\
\hline Clinical trials & Data entry, registry management and protocol execution of clinical trials; research accounting and administration \\
\hline Physiotherapy & Assessment of exercise capacity. Guidance related to exercise programmes for appropriate patients \\
\hline Social work & $\begin{array}{l}\text { Emotional adjustment and counseling for patients and families; assessment of resources required; referral to appropriate } \\
\text { community agencies; patient and family planning }\end{array}$ \\
\hline Dietetics & Assessment of nutritional status and requirements; implementation of appropriate diet plan; patient and family education \\
\hline Pharmacy & Consultation for matters relating to drug therapy; patient and family education \\
\hline Rehabilitation & Assessment of impairment and disability; patient and family education \\
\hline Radiology & Diagnostic evaluation; echocardiography \\
\hline Transplantation & Patient evaluation, surgical and medical treatment; patient and family education \\
\hline
\end{tabular}


Analysis of the observations and interviews with participants about their perceptions of the multidisciplinary structure revealed several common elements related to the success of a unit. These include, but are not limited to:

- A team approach, involving core disciplines integral to the provision of PAH management, with input from other specialties as required (where 'core' disciplines are cardiology, rheumatology, respiratory, radiology, and supportive care).

- Communication among team members regarding treatment planning via regular multidisciplinary meetings held at regular times, venues and with consistent formats to the delivery of information.

- Equivalent access to care for all patients, regardless of geographical location.

- Provision of care in accord with international guidelines.

Strong leadership was also raised by several members as a key element to the success of the multidisciplinary team: coordinating and chairing regular meetings, encouraging involvement of all participants in case discussions and decision-making and, at the conclusion of case discussions, summarizing the discussion and inviting any further input before moving to the next case. Motivational factors for attending meetings included, 1) perceived benefits of the meetings for both meeting participants and patients, 2) an opportunity to interact with other members of the multidisciplinary team in an inclusive atmosphere, 3 ) an opportunity for educational interaction and professional development, and 4) streamlining of referral pathways. Meetings may also serve as a resource of identifying patients suitable for clinical trial participation. An established center for managing disease also allows for the collection of registry data on patient presentations, patterns of care and treatment outcomes. This provides a comprehensive set of information available to guide future management, clinical research and treatment practices.

Clearly, the way in which multidisciplinary care is best structured and implemented will vary between sites and depend on local, political and financial resources. For example, geographical remoteness may require collaborations to use telemedicine for multidisciplinary case conferencing. In other situations, the appointment of a nurse coordinator as a focal point for patients being treated by several facilities within a collaborative may represent an avenue of streamlining patient care and ensuring that patients are managed according to agreed guidelines and receive adequate follow-up. However, regardless of the structure in place, the diverse nature and complexity of PAH is an area of medicine in need of multidisciplinary care. The next step, and an avenue for future research, will be to evaluate whether care provided by a multidisciplinary team can improve longterm outcomes in patients with PAH, as has been the case in patients suffering from heart failure ${ }^{82}$ and stroke. ${ }^{83,84}$

\section{Conclusion}

The treatment of PAH has realized dramatic advances over the past decade, and it is clear that the PAH-specific therapies can significantly alter the natural history of the disease. Despite this, there remains a need to identify patients with PAH earlier, before the onset of extensive vascular remodeling. This can be achieved by performing a thorough assessment to rule out other diagnostic possibilities and to establish the type of PAH. Once identified, it is essential that patients are provided with adequate care and follow-up in line with evidence-based guidelines. Effective diagnosis and treatment of PAH is complex and challenging, relying on the expertise of a team of specialists including rheumatologists, respiratory physicians, cardiologists and specialized nurses. The collaboration of a well coordinated multidisciplinary team of healthcare professionals accounts for the most optimal diagnostic and therapeutic procedures and ensures that patients receive the best possible care.

\section{Disclosures}

EG has received research support from Actelion Pharmaceuticals Australia and CSL as well as honoraria for speaking and consulting engagements, and as a member of the Actelion, CSL and GSK Advisory Boards. The Heart and Lung Transplant Foundation of WA, of which EG is chair has received educational grants from Actelion, and CSL. EG has also received travel support from Bayer-Schering the manufacturers of iloprost, Encysive Pharmaceuticals, the manufacturers of sitaxentan and GSK, the distributors of ambrisentan in Australia.

GS is an employee of Actelion Pharmaceuticals Australia. $\mathrm{BD}$ has received consulting fees from Actelion.

\section{References}

1. Shafazand S, Goldstein MK, Doyle RL, Hlatky MA, Gould MK. Healthrelated quality of life in patients with pulmonary arterial hypertension. Chest. 2004;126:1452-1459.

2. D'Alonzo GE, Barst RJ, Ayres SM, et al. Survival in patients with primary pulmonary hypertension. Results from a national prospective registry. Ann Intern Med. 1991;115:343-349.

3. McLaughlin VV, Sitbon O, Badesch DB, et al. Survival with first-line bosentan in patients with primary pulmonary hypertension. Eur Respir J. 2005;25:244-249. 
4. Williams MH, Das C, Handler CE, et al. Systemic sclerosis associated pulmonary hypertension: improved survival in the current era. Heart 2006;92:926-932.

5. Rich S, Dantzker DR, Ayres SM, et al. Primary pulmonary hypertension A national prospective study. Ann Intern Med. 1987;107:216-223.

6. Simonneau G, Galie N, Rubin LJ, et al. Clinical classification of pulmonary hypertension. J Am Coll Cardiol. 2004;43:5S-12S.

7. Galie N, Torbicki A, Barst R, et al. Guidelines on diagnosis and treatment of pulmonary arterial hypertension. The Task Force on Diagnosis and Treatment of Pulmonary Arterial Hypertension of the European Society of Cardiology. Eur Heart J. 2004;25:2243-2278.

8. Rubin LJ. Diagnosis and management of pulmonary arterial hypertension: ACCP evidence-based clinical practice guidelines. Chest. 2004;126:7S-10S

9. Runo JR, Loyd JE. Primary pulmonary hypertension. Lancet. 2003;361:1533-1544.

10. Rich S. Executive summary from the world symposium on primary pulmonary hypertension. Available at http://www.who.int/ncd/cvd/pph. htm. 1998

11. Magliano M, Isenberg DA, Hillson J. Pulmonary hypertension in autoimmune rheumatic diseases: where are we now? Arthritis Rheum. 2002;46:1997-2009.

12. Fuster V, Steele PM, Edwards WD, Gersh BJ, McGoon MD, Frye RL. Primary pulmonary hypertension: natural history and the importance of thrombosis. Circulation. 1984;70:580-587.

13. Hoeper MM, Galie N, Simonneau G, Rubin LJ. New treatments for pulmonary arterial hypertension. Am J Respir Crit Care Med. 2002;165:1209-1216.

14. Kim NH, Rubin LJ. Endothelin in health and disease: endothelin receptor antagonists in the management of pulmonary artery hypertension. J Cardiovasc Pharmacol Ther. 2002;7:9-19.

15. Rubin LJ, Roux S. Bosentan: a dual endothelin receptor antagonist. Expert Opin Investig Drugs. 2002;11:991-1002.

16. Roux S, Breu V, Ertel SI, Clozel M. Endothelin antagonism with bosentan: a review of potential applications. J Mol Med. 1999;77:364-376.

17. Humbert M, Morrell NW, Archer SL, et al. Cellular and molecular pathobiology of pulmonary arterial hypertension. J Am Coll Cardiol. 2004;43:13S-24S

18. Barst RJ. PDGF signaling in pulmonary arterial hypertension. J Clin Invest. 2005;115:2691-2694.

19. McGoon M, Gutterman D, Steen V, et al. Screening, early detection, and diagnosis of pulmonary arterial hypertension: ACCP evidence-based clinical practice guidelines. Chest. 2004;126:14S-34S.

20. Proudman SM, Stevens WM, Sahhar J, Celermajer D. Pulmonary arterial hypertension in systemic sclerosis: the need for early detection and treatment. Intern Med J. 2007;37:485-494.

21. Hachulla E, Coghlan JG. A new era in the management of pulmonary arterial hypertension related to scleroderma: endothelin receptor antagonism. Ann Rheum Dis. 2004;63:1009-1014.

22. Humbert M, Sitbon O, Chaouat A, et al. Pulmonary arterial hypertension in France: results from a national registry. Am J Respir Crit Care Med. 2006;173:1023-1030.

23. Peacock AJ, Murphy NF, McMurray JJ, Caballero L, Stewart S. An epidemiological study of pulmonary arterial hypertension. Eur Respir J. 2007;30:104-109.

24. Rubin LJ. Primary pulmonary hypertension. $N$ Engl J Med. 1997;336:111-117.

25. Gaine SP, Rubin LJ. Primary pulmonary hypertension. Lancet. 1998;352:719-725.

26. Galie N, Manes A, Uguccioni L, et al. Primary pulmonary hypertension: insights into pathogenesis from epidemiology. Chest. 1998;114 184S-194S.

27. Battle RW, Davitt MA, Cooper SM, et al. Prevalence of pulmonary hypertension in limited and diffuse scleroderma. Chest. 1996;110:1515-1519.

28. Koh ET, Lee P, Gladman DD, Abu-Shakra M. Pulmonary hypertension in systemic sclerosis: an analysis of 17 patients. Br J Rheumatol. 1996;35:989-993.
29. MacGregor AJ, Canavan R, Knight C, et al. Pulmonary hypertension in systemic sclerosis: risk factors for progression and consequences for survival. Rheumatology (Oxford). 2001;40:453-459.

30. Pope JE, Lee P, Baron M, et al. Prevalence of elevated pulmonary arterial pressures measured by echocardiography in a multicenter study of patients with systemic sclerosis. J Rheumatol. 2005;32:1273-1278.

31. Schachna L, Wigley FM, Chang B, White B, Wise RA, Gelber AC. Age and risk of pulmonary arterial hypertension in scleroderma. Chest. 2003;124:2098-2104.

32. Gabbay E, Yeow W, Playford D. Pulmonary arterial hypertension is an uncommon cause of pulmonary hypertension in an unselected population: The Armadale echocardiography study. Proceedings of the American Thoracic Society Annual Meeting; 2007 May 18-23; San Francisco, California.

33. Consensus statement on the management of pulmonary hypertension in clinical practice in the UK and Ireland. Heart. 2008;94 Suppl 1:11-41.

34. Nauser TD, Stites SW. Diagnosis and treatment of pulmonary hypertension. Am Fam Physician. 2001;63:1789-1798.

35. Barst RJ, McGoon M, Torbicki A, et al. Diagnosis and differential assessment of pulmonary arterial hypertension. J Am Coll Cardiol. 2004; 43:40S-47S.

36. Borgeson DD, Seward JB, Miller FA, Jr, Oh JK, Tajik AJ. Frequency of Doppler measurable pulmonary artery pressures. J Am Soc Echocardiogr. 1996;9:832-837.

37. Barst RJ, editor. Pulmonary arterial hypertension: Evidence-based treatment. Wiltshire: Wiley; 2008.

38. Phung S, Strange G, Chung LP, et al. Prevalence of pulmonary arterial hypertension in an Australian scleroderma population: Screening allows for earlier diagnosis. Intern Med J. 2008.

39. Badesch DB, Abman SH, Ahearn GS, et al. Medical therapy for pulmonary arterial hypertension: ACCP evidence-based clinical practice guidelines. Chest. 2004;126:35S-62S.

40. Doyle RL, McCrory D, Channick RN, Simonneau G, Conte J. Surgical treatments/interventions for pulmonary arterial hypertension: ACCP evidence-based clinical practice guidelines. Chest. 2004;126:63S-71S.

41. McLaughlin VV, Presberg KW, Doyle RL, et al. Prognosis of pulmonary arterial hypertension: ACCP evidence-based clinical practice guidelines. Chest. 2004;126:78S-92S.

42. Ogata M, Ohe M, Shirato K, Takishima T. Effects of a combination therapy of anticoagulant and vasodilator on the long-term prognosis of primary pulmonary hypertension. Jpn Circ J. 1993;57:63-69.

43. Rich S, Kaufmann E, Levy PS. The effect of high doses of calciumchannel blockers on survival in primary pulmonary hypertension. N Engl J Med. 1992;327:76-81.

44. Barst RJ, Rubin LJ, Long WA, et al. A comparison of continuous intravenous epoprostenol (prostacyclin) with conventional therapy for primary pulmonary hypertension. The Primary Pulmonary Hypertension Study Group. N Engl J Med. 1996;334:296-302.

45. Stewart S, Strange G, editors. A clinician's guide to pulmonary arterial hypertension. Second edition: Informa Healthcare; 2008.

46. Galie N, Manes A, Branzi A. The endothelin system in pulmonary arterial hypertension. Cardiovasc Res. 2004;61:227-237.

47. Stewart DJ, Levy RD, Cernacek P, Langleben D. Increased plasma endothelin-1 in pulmonary hypertension: marker or mediator of disease? Ann Intern Med. 1991;114:464-469.

48. Channick RN, Simonneau G, Sitbon O, et al. Effects of the dual endothelin-receptor antagonist bosentan in patients with pulmonary hypertension: a randomised placebo-controlled study. Lancet. 2001;358:1119-1123.

49. Jais X, D’Armini AM, Jansa P, et al. Bosentan for treatment of inoperable chronic thromboembolic pulmonary hypertension: BENEFiT (Bosentan Effects in iNopErable Forms of chronIc Thromboembolic pulmonary hypertension), a randomized, placebo-controlled trial. J Am Coll Cardiol. 2008;52:2127-2134.

50. Gatzoulis MA, Beghetti M, Galie N, et al. Longer-term bosentan therapy improves functional capacity in Eisenmenger syndrome: results of the BREATHE-5 open-label extension study. Int J Cardiol. 2008;127:27-32. 
51. Galie N, Rubin L, Hoeper M, et al. Treatment of patients with mildly symptomatic pulmonary arterial hypertension with bosentan (EARLY study): a double-blind, randomised controlled trial. Lancet. 2008;371:2093-2100.

52. Rubin LJ, Badesch DB, Barst RJ, et al. Bosentan therapy for pulmonary arterial hypertension. $N$ Engl J Med. 2002;346:896-903.

53. Barst RJ, Ivy D, Dingemanse J, et al. Pharmacokinetics, safety, and efficacy of bosentan in pediatric patients with pulmonary arterial hypertension. Clin Pharmacol Ther. 2003;73:372-382.

54. Sitbon O, Gressin V, Speich R, et al. Bosentan for the treatment of human immunodeficiency virus-associated pulmonary arterial hypertension. Am J Respir Crit Care Med. 2004;170:1212-1217.

55. Denton CP, Pope JE, Peter HH, et al. Long-term effects of bosentan on quality of life, survival, safety and tolerability in pulmonary arterial hypertension related to connective tissue diseases. Ann Rheum Dis. 2008;67:1222-1228.

56. Galie N, Hinderliter AL, Torbicki A, et al. Effects of the oral endothelinreceptor antagonist bosentan on echocardiographic and doppler measures in patients with pulmonary arterial hypertension. $\mathrm{J} \mathrm{Am} \mathrm{Coll}$ Cardiol. 2003;41:1380-1386.

57. Humbert M, Segal ES, Kiely DG, Carlsen J, Schwierin B, Hoeper MM. Results of European post-marketing surveillance of bosentan in pulmonary hypertension. Eur Respir J. 2007;30:338-344.

58. Barst RJ, Langleben D, Badesch D, et al. Treatment of pulmonary arterial hypertension with the selective endothelin-A receptor antagonist sitaxsentan. J Am Coll Cardiol. 2006;47:2049-2056.

59. Barst RJ, Langleben D, Frost A, et al. Sitaxsentan therapy for pulmonary arterial hypertension. Am J Respir Crit Care Med. 2004;169: $441-447$.

60. Benza RL, Barst RJ, Galie N, et al. Sitaxsentan for the treatment of pulmonary arterial hypertension: a 1-year, prospective, open-label observation of outcome and survival. Chest. 2008;134:775-782.

61. Galie N, Badesch D, Oudiz R, et al. Ambrisentan therapy for pulmonary arterial hypertension. J Am Coll Cardiol. 2005;46:529-535.

62. Barst RJ, Rubin LJ, McGoon MD, Caldwell EJ, Long WA, Levy PS. Survival in primary pulmonary hypertension with long-term continuous intravenous prostacyclin. Ann Intern Med. 1994;121:409-415.

63. McLaughlin VV, Shillington A, Rich S. Survival in primary pulmonary hypertension: the impact of epoprostenol therapy. Circulation. 2002;106:1477-1482.

64. Sitbon O, Humbert M, Nunes H, et al. Long-term intravenous epoprostenol infusion in primary pulmonary hypertension: prognostic factors and survival. J Am Coll Cardiol. 2002;40:780-788.

65. Galie N, Ghofrani HA, Torbicki A, et al. Sildenafil citrate therapy for pulmonary arterial hypertension. $N$ Engl J Med. 2005;353: 2148-2157.

66. McLaughlin VV, Gaine SP, Barst RJ, et al. Efficacy and safety of treprostinil: an epoprostenol analog for primary pulmonary hypertension. J Cardiovasc Pharmacol. 2003;41:293-299.

67. Provencher S, Sitbon O, Simonneau G. Treatment of pulmonary arterial hypertension with bosentan: from pathophysiology to clinical evidence. Expert Opin Pharmacother. 2005;6:1337-1348.
68. Hoeper MM, Markevych I, Spiekerkoetter E, Welte T, Niedermeyer J. Goal-oriented treatment and combination therapy for pulmonary arterial hypertension. Eur Respir J. 2005;26:858-863.

69. Opitz CF, Wensel R, Winkler J, et al. Clinical efficacy and survival with first-line inhaled iloprost therapy in patients with idiopathic pulmonary arterial hypertension. Eur Heart J. 2005;26:1895-1902.

70. Simonneau G, Rubin LJ, Galie N, et al. Addition of sildenafil to long-term intravenous epoprostenol therapy in patients with pulmonary arterial hypertension: a randomized trial. Ann Intern Med. 2008;149:521-530.

71. Recommendations on the management of pulmonary hypertension in clinical practice. Heart. 2001;86 Suppl 1:I1-13.

72. Sandoval J, Rothman A, Pulido T. Atrial septostomy for pulmonary hypertension. Clin Chest Med. 2001;22:547-560.

73. Taichman DB, Shin J, Hud L, et al. Health-related quality of life in patients with pulmonary arterial hypertension. Respir Res. 2005;6:92.

74. Archibald CJ, Auger WR, Fedullo PF, et al. Long-term outcome after pulmonary thromboendarterectomy. Am J Respir Crit Care Med. 1999;160:523-528.

75. Mikhail GW, Prasad SK, Li W, et al. Clinical and haemodynamic effects of sildenafil in pulmonary hypertension: acute and mid-term effects. Eur Heart J. 2004;25:431-436.

76. Olschewski H, Simonneau G, Galie N, et al. Inhaled iloprost for severe pulmonary hypertension. $N$ Engl J Med. 2002;347:322-329.

77. Sastry BK, Narasimhan C, Reddy NK, Raju BS. Clinical efficacy of sildenafil in primary pulmonary hypertension: a randomized, placebo-controlled, double-blind, crossover study. J Am Coll Cardiol. 2004;43:1149-1153.

78. Simonneau G, Barst RJ, Galie N, et al. Continuous subcutaneous infusion of treprostinil, a prostacyclin analogue, in patients with pulmonary arterial hypertension: a double-blind, randomized, placebocontrolled trial. Am J Respir Crit Care Med. 2002;165:800-804.

79. Souza R, Jardim C, Martins B, et al. Effect of bosentan treatment on surrogate markers in pulmonary arterial hypertension. Curr Med Res Opin. 2005;21:907-911.

80. Strange G, Gabbay E, Williams T, Wlodarczyk J, McNeil K, Keogh A. Bosentan therapy in patients with pulmonary arterial hypertension: the relationship between improvements in six-minute walk test and quality of life. Respirology. 2008;13:674-682.

81. Mereles D, Ehlken N, Kreuscher S, et al. Exercise and respiratory training improve exercise capacity and quality of life in patients with severe chronic pulmonary hypertension. Circulation. 2006;114:1482-1489.

82. McDonald K, Ledwidge M, Cahill J, et al. Heart failure management: multidisciplinary care has intrinsic benefit above the optimization of medical care. J Card Fail. 2002;8:142-148.

83. Organised inpatient (stroke unit) care for stroke. Stroke Unit Trialists' Collaboration. Cochrane Database Syst Rev. 2000:CD000197.

84. Hankey GJ, Warlow CP. Treatment and secondary prevention of stroke: evidence, costs, and effects on individuals and populations. Lancet. 1999;354:1457-1463.

85. August DA, Carpenter LC, Harness JK, et al. Benefits of a multidisciplinary approach to breast care. J Surg Oncol. 1993;53:161-167.
Journal of Multidisciplinary Healthcare

\section{Publish your work in this journal}

The Journal of Multidisciplinary Healthcare is an international, peerreviewed open-access journal that aims to represent and publish research in healthcare areas delivered by practitioners of different disciplines. This includes studies and reviews conducted by multidisciplinary teams as well as research which evaluates the results or conduct of such teams or Submit your manuscript here: http://www.dovepress.com/journal-of-multidisciplinary-healthcare-journal

\section{Dovepress}

healthcare processes in general. The journal covers a wide range of areas and welcomes submission from practitioners at all levels, from all over the world. The manuscript management system is completely online and includes a very quick and fair peer-review system. Visit http://www.dovepress.com/testimonials.php to read real quotes from published authors. 